\title{
A FICÇÃO CIENTÍfICA DE JÚLIO VERNE E O ENSINO DE FÍSICA: UMA ANÁLISE DE "VINTE MIL LÉGUAS SUBMARINAS" "*
}

\author{
Júlio César David Ferreira \\ Doutorando em Educação \\ Programa de Pós-Graduação em Educação - UFPR \\ Curitiba - PR \\ Paulo César de Almeida Raboni \\ Departamento de Educação \\ Programa de Pós-Graduação em Educação \\ Faculdade de Ciências e Tecnologia - UNESP \\ Presidente Prudente - SP
}

\begin{abstract}
Resumo
Este artigo apresenta os resultados de uma pesquisa sobre a obra literária de Júlio Verne no contexto do ensino de conceitos científicos. No livro "Vinte Mil Léguas Submarinas", tomando Bakhtin como referencial de análise, encontramos uma sistematização e intencionalidade de ensinar conceitos por parte de Verne. Notamos uma proximidade entre as situações descritas pelo autor e os enunciados de fenômenos físicos típicos de livros didáticos do Ensino Médio, com algumas diferenças: a riqueza e complexidade das narrativas de Verne, com enredos que tornam os conceitos cientificos altamente contextualizados e que ampliam as possibilidades de compreensão do leitor. Nesse sentido, a aproximação de diferentes gêneros discursivos possibilita o surgimento dos interdis-
\end{abstract}

\footnotetext{
Jules Verne's Science Fiction and the Physics Teaching: an analysis of "Twenty Thousand Leagues Underwater"

* Recebido: agosto de 2012.

Aceito: março de 2013.
} 
cursos que a leitura pode produzir, ou, trazendo para o contexto do ensino de Física, na literatura de Verne encontramos diversos pontos de apoio para a compreensão do conhecimento científico presente no discurso escolar.

Palavras-chave: Júlio Verne. Ficção Científica. Ensino de Física.

\begin{abstract}
This article presents the results of a research on the literary work of Jules Verne in the context of the teaching of scientific concepts. In the book "Twenty Thousand Leagues Under the Sea", taking Bakhtin as reference for analysis, we find a systematic and deliberate teaching concepts by Verne. We note a similarity between the situations described by the author and the statements of physical phenomena typical of high school textbooks, with some differences: the richness and complexity of the Verne's narrative, with plots that make highly contextualized the scientific concepts and that expand the possibilities for the reader's understanding. Accordingly, the approach of different genres allows the emergence of interdiscourses that reading can produce, or, in the context of Physics Education, we find in the Verne's literature various points of support for the understanding of scientific knowledge in this school discourse.
\end{abstract}

Keywords: Jules Verne. Science Fiction. Physics Teaching.

\title{
I. Introdução
}

Neste artigo, temos como objeto de estudo algumas relações entre a literatura de ficção de Júlio Verne e o ensino de Física. Tomamos como exemplo para análise o livro "Vinte Mil Léguas Submarinas" (1870), de Júlio Verne, no contexto do ensino de conceitos científicos próprios da Física, mas o mesmo pode ser feito para a quase totalidade da obra do escritor francês. Vemos, na ficção científica desse renomado autor, características favoráveis à divulgação das ciências, à apresentação de conceitos e à contextualização dos conteúdos presentes nos livros didáticos. 
Em concordância com Zanetic (1989, 2005, 2006), acreditamos que áreas distintas do conhecimento, como a ciência e a literatura, podem se relacionar harmoniosamente, tanto dentro como fora do ambiente escolar, propiciando às pessoas uma compreensão mais completa e efetiva do mundo. Centramos nossas atenções na literatura de Júlio Verne, observando o papel que a Física desempenha nesse cenário.

O conhecimento científico é especializado e rompe com o conhecimento cotidiano na sua constituição. Como apontam Robilotta e Babichak (1997), a apropriação do conhecimento científico pelos estudantes depende da (re)construção de conceitos que se entrelaçam, formando uma rede complexa que se lança na compreensão de uma importante dimensão da realidade.

A compreensão dos enunciados da Física depende de mais de uma linguagem - inclui a matemática, a imagética, a audiovisual, entre outras. Contudo, as aulas de Física têm sido restritas à linguagem textual, acompanhada dos signos matemáticos e físicos, de modo que a grande maioria dos estudantes encontra muita dificuldade na interpretação de leis, postulados, enunciados de problemas e outros, bem como na compreensão do mundo a partir dessas leis, limitando-se quase sempre à aplicação de equações sobre as quais pouco sabem falar. Nas aulas, os diferentes gêneros do discurso - o escolar, o científico escolar e o do cotidiano do aluno - dão à esfera do ensino e da aprendizagem da Física um caráter heterogêneo, o que possibilita deslocamentos no processo de construção de sentidos pelos alunos. Esses deslocamentos são quase sempre ignorados, ou tratados como obstáculos ao aprendizado.

No tocante à leitura - não só dos textos científicos, mas dos mais variados gêneros - Geraldi (2006) assinala que a relação de um leitor com um texto pode ser orientada por quatro posturas:

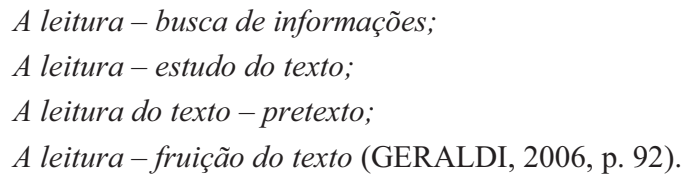

No Brasil, poucos alunos do Ensino Médio transitam com fluência entre tais posturas diante dos textos. Os estudantes não se posicionam ativamente ou desenvolvem um senso crítico sobre a leitura que realizam. De acordo com o último relatório do Pisa (Programme for International Student Assessment), referente à avaliação de 2009, o Brasil está entre os países cujos índices de leitura mais cresceram, entretanto, o país ainda tem muito a melhorar, se considerarmos que $49,6 \%$ 
dos estudantes avaliados se encontram em níveis insatisfatórios de proficiência (INEP, 2013).

Embora a Física envolva vários tipos de leitura, os textos predominantes nos livros didáticos mais utilizados pelos professores são curtos, enxutos, com pouca ou nenhuma referência a elementos próximos ao aluno, constituindo o material que melhor se adapta ao padrão fragmentado de aula. A leitura de fruição é quase inexistente devido à falta de contextualização dos conceitos científicos. Em muitos casos, os estudantes acabam traumatizados diante das dificuldades e perdem completamente o interesse pela disciplina, o que significa um grande obstáculo ao processo de aprendizagem. Megid Neto e Fracalanza confirmam essa característica do livro didático de ciências, e acrescentam:

Apesar de todos os esforços empreendidos até o momento, ainda não se alterou o tratamento dado ao conteúdo presente no livro que configura erroneamente o conhecimento cientifico como um produto acabado, elaborado por mentes privilegiadas, desprovidas de interesses político-econômicos e ideológicos, ou seja, que apresenta o conhecimento sempre como verdade absoluta, desvinculado do contexto histórico e sociocultural (MEGID NETO; FRACALANZA, 2003, p. 151).

A nosso ver, a utilização dos livros didáticos não pode ocorrer em detrimento de outros elementos didáticos para estabelecer contato com os objetos de estudo. A leitura de textos de ficção que incorporam elementos científicos, como a encontrada em Júlio Verne, por exemplo, pode preencher a lacuna existente entre o conhecimento físico ensinado e o conhecimento cotidiano do aluno. Verne é um contraponto para essa distância que se instala entre as áreas do conhecimento, pois apresenta um mundo rico de possibilidades, onde o conhecimento científico se materializa de modo amistoso. Suas obras falam da humanidade e de seu futuro com grande entusiasmo, antecipando vários avanços no mundo tecnológico que estava prestes a se inaugurar, no final do século XIX.

\section{Procedimentos metodológicos}

A seguir, apresentaremos os procedimentos metodológicos pelos quais conduzimos nosso trabalho, que, em princípio, consistiu-se em uma pesquisa geral da obra de Júlio Verne, a partir da qual notamos evidências que corroboravam nossa ideia inicial: é possível aproximar a literatura de Júlio Verne do contexto do ensino de Física do Ensino Médio. 
Realizando uma análise documental de caráter qualitativo, com a leitura do livro "Vinte Mil Léguas Submarinas" e a seleção de alguns trechos, procuramos discutir as relações entre a obra de Júlio Verne e o ensino de Física, tomando como categorias de análise alguns conceitos da teoria de Bakhtin (1997, 2009): gêneros do discurso, tema, significação, réplica e dialogismo.

Com uma teoria unificadora da linguagem, Bakhtin conseguiu abordar e relacionar os mais diversos aspectos antes separados por disciplinas próprias da linguística, enriquecendo o estudo da linguagem em seu caráter mais notável, o da comunicação, através dos enunciados. Seus estudos definem o enunciado como unidade da comunicação verbal, sendo a oração definida como unidade da língua: "Cada enunciado é um elo da cadeia muito complexa de outros enunciados" (BAKHTIN, 1997, p. 291).

Para Bakhtin (2009), cada enunciação pode possuir um sentido definido e único, uma significação unitária. Tal propriedade é o que garante o sentido da enunciação completa, o qual podemos definir como tema da enunciação, que deve ser único. O tema constitui o "estágio superior real da capacidade linguística de significar", enquanto a significação é o "estágio inferior da capacidade de significar”. Enquanto o tema depende da situação histórica concreta onde a enunciação foi proferida, a significação é idêntica em todas as instâncias históricas.

O dialogismo é visto na teoria bakhtiniana como um diálogo entre discursos. Os interlocutores assumem esse aspecto ao desenvolver seus enunciados inscritos sócio-historicamente. $\mathrm{O}$ discurso assume várias manifestações, que vão além da simples combinação das palavras e orações.

Quem fala ocupa um lugar social, histórico e ideológico, constituintes de seu discurso. "A fala só existe, na realidade, na forma concreta dos enunciados de um indivíduo: do sujeito de um discurso-fala. $\mathrm{O}$ discurso se molda sempre à forma do enunciado que pertence a um sujeito falante e não pode existir fora dessa forma" (BAKHTIN, 1997, p. 293).

No ato da comunicação, do diálogo entre os discursos, é necessário o emprego de um gênero para a sua composição, os gêneros do discurso ou gêneros discursivos. Não se emprega, em uma conversa familiar ou íntima, por exemplo, o mesmo gênero utilizado no âmbito acadêmico.

Bakhtin realizou um amplo estudo sobre os gêneros do discurso. Em "Estética da Criação Verbal" (1997), ressaltou a riqueza e heterogeneidade dos gêneros discursivos utilizados pelo homem:

A riqueza e a variedade dos gêneros do discurso são infinitas, pois a variedade virtual da atividade humana é inesgotável, e cada esfera dessa ativi- 
dade comporta um repertório de gêneros do discurso que vai diferenciandose e ampliando-se à medida que a própria esfera se desenvolve e fica mais complexa. Cumpre salientar de um modo especial a heterogeneidade dos gêneros do discurso (orais e escritos), que incluem indiferentemente: a curta réplica do diálogo cotidiano (com a diversidade que este pode apresentar conforme os temas, as situações e a composição de seus protagonistas), o relato familiar, a carta (com suas variadas formas), a ordem militar padronizada, em sua forma lacônica e em sua forma de ordem circunstanciada, o repertório bastante diversificado dos documentos oficiais (em sua maioria padronizados), o universo das declarações públicas (num sentido amplo, as sociais, as politicas) (BAKHTIN, 1997, p. 279-280).

A diversidade de gêneros discursivos presente na comunicação humana é uma característica que emana das numerosas esferas sociais nas quais estamos inseridos. As esferas de comunicação discursiva dão esse caráter heterogêneo à comunicação.

A análise dos gêneros discursivos, por exemplo, permite verificar, em algumas narrativas de Júlio Verne, a presença de conceitos/assuntos científicos muito bem estruturados, ao passo que, em outras, o rigor conceitual não é predominante, o que dá à sua obra um caráter heterogêneo no que tange à diversidade de leituras possíveis e dos gêneros discursivos envolvidos.

O conceito de tema, que para Bakhtin (2009) se configura como o "estágio superior real da capacidade linguística de significar", proporciona uma comparação das formas como são apresentados os conteúdos da Física nos livros didáticos e nos livros de Júlio Verne. Nos manuais escolares atuais, em diversos casos, os conceitos são exibidos de maneira sintética, asséptica e desprovidos de elementos contextualizadores, enquanto na obra de Verne, os processos dialógicos são amplos. Neste artigo, essas e outras características serão exemplificadas, mas cumpre destacar que não intentamos em nossa pesquisa uma comparação e/ou hierarquização entre livros didáticos e livros de ficção científica. São produções com finalidades diferentes, elaboradas sob condições diversas e, principalmente, utilizadas com desígnios particulares. Contudo, não podemos desconsiderar as semelhanças e diferenças que podem nelas ser encontradas, tampouco as reflexões sobre essas características que podem representar novas perspectivas para o ensino de Física.

A significação, que para Bakhtin (2009) é o "estágio inferior da capacidade de significar", é o contraponto para o conceito de tema. Uma significação é idêntica em qualquer instância histórica, cultural e social, devido ao fato de seus 
elementos constituintes serem abstratos, convencionais, sem existência concreta independente, mas que também são indispensáveis para a constituição enunciativa. Para Bakhtin, a verdadeira compreensão dos enunciados é ativa e responsiva, permitindo a constituição de réplicas, e isso só é possível diante da riqueza na composição dos temas. Os livros didáticos dificultam esse processo quando exibem os conceitos científicos - ou parte deles - de forma simplificada e descontextualizada.

Os processos dialógicos são fundamentais na teoria bakhtiniana. É através do dialogismo que o autor "conversa" com o leitor, que ambos dialogam consigo mesmos e, antes de tudo, os discursos dialogam com outros discursos por meio de múltiplas vozes. Na análise de "Vinte Mil Léguas Submarinas", realizamos uma reflexão sobre o diálogo entre a literatura de Júlio Verne e a ciência representada pelos conceitos/assuntos próprios da Física.

\section{Análise e resultados}

Com o respaldo teórico de Bakhtin (1997), notamos, em "Vinte Mil Léguas Submarinas", relações díspares entre o gênero discursivo utilizado por Júlio Verne, e o científico, representado pela Física. Pode-se dizer que o autor utiliza em suas narrativas uma linguagem bilateral, em que o discurso científico se entrelaça com o literário.

Em várias passagens do livro, como a citada em seguida, notam-se expressões de caráter fantasioso e situações de aventura em ambientes peculiares, reforçadas, entretanto, pela linguagem científica, pelos signos numéricos:

[...] Pois bem! Suponhamos a arma dez vezes maior e o animal dez vezes mais possante. Lancemo-lo com a velocidade de vinte milhas por hora. Multipliquemos a massa pela velocidade, e teremos choque capaz de produzir a catástrofe referida (VERNE, 1972, p. 19, grifo nosso).

Nesse trecho, notamos o conceito de quantidade de movimento linear ${ }^{1}$. Uma característica nos chama a atenção nessa narrativa: a apresentação de uma situação em que o conceito pode ser utilizado para compreender o fenômeno e, neste processo, o próprio conceito toma um sentido. Está contextualizado, enredado pelos riscos de uma catástrofe que poderia ocorrer na colisão de uma embarca-

\footnotetext{
1 A quantidade de movimento linear (também chamada de momento linear ou momentum linear) é uma grandeza Física dada pelo produto vetorial da massa pela velocidade de um corpo. Sua unidade de medida no Sistema Internacional de Unidades (SI) é o (Kg.m/s) (HALLIDAY et al., 2002).
} 
ção com uma fera marinha. O mesmo conceito pode ser ilustrado na Fig. 1, como segue, em Ramalho Júnior et al. (1988, p. 240):

Considere um corpo de massa $m$ com velocidade $\vec{v}$ num determinado referencial. A quantidade de movimento desse corpo é a grandeza vetorial:

$$
\vec{Q}=m \vec{v}
$$

Quantidade de movimento é uma grandeza vetorial e possui, portanto, intensidade, direção e sentido.

$$
\vec{Q}=m \vec{v}
$$

a) intensidade: (módulo) $|\vec{Q}|=m|\vec{v}|$

b) direção: a mesma de $\vec{v}$ (paralela a $\vec{v}$ )

c) sentido: o mesmo de $\vec{v}$ (pois mé positivo)

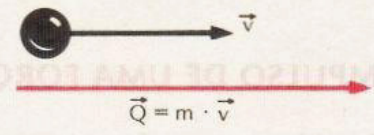

Fig. 4

Fig. 1 - Quantidade de movimento.

A representação vetorial em corpos genéricos é frequente nos livros didáticos. A nosso ver, esse também é um meio importante de apresentar os conceitos, entretanto, envolve um conhecimento prévio que é perpassado pela intrínseca relação do objeto estudado com o seu mapa conceitual (ROBILOTTA; BABICHAK, 1997), ou seja, não traz em si mesmo a possibilidade de uma compreensão mais efetiva do objeto estudado, ficando restrito ao campo teórico e desprovido de elementos da realidade. Recorrendo a Bakhtin (1997, 2009), acreditamos que, no referido trecho, Verne aborda não só o conceito de quantidade de movimento linear, mas suas relações em um contexto mais amplo, repleto de elementos composicionais verbais e não verbais. Tais características revestem essa abordagem de potencial para a produção de réplicas pelo aluno leitor e, consequentemente, para uma compreensão mais efetiva do que proporcionaria a interpretação isolada de diagramas com representações vetoriais. O uso exclusivo de formas abstratas de representação da realidade reduz as possibilidades de réplica pelo aluno. A réplica é entendida por Bakhtin como a elaboração feita por aquele que ouve um enunciado, e ela pode se manifestar em voz alta ou não. Os sentidos construídos durante um diálogo constituem a réplica, elaborada pelos falantes. Sobre ela, esclarece Bakhtin:

Compreender a enunciação de outrem significa orientar-se em relação a ela, encontrar o seu lugar adequado no contexto correspondente. A cada pa- 
lavra da enunciação que estamos em processo de compreender, fazemos corresponder uma série de palavras nossas, formando uma réplica. Quanto mais numerosas e substanciais forem, mais profunda e real é a nossa compreensão (BAKHTIN, 2009, p. 137, grifo nosso).

Um aluno do Ensino Médio, ao ouvir as explicações sobre um fenômeno ou uma teoria, busca pontos de apoio em suas vivências (escolares ou não) para compreender os enunciados. Sustentamos na teoria da enunciação, e em especial no conceito de réplica, a afirmação de que quanto mais elementos da vivência dos alunos estiverem presentes nas explicações dos professores, maiores são as condições de construção de sentidos para o que se ouve, ou, em outros termos, para o aprendizado. Os fenômenos presentes na obra de Júlio Verne são descritos com riqueza de detalhes, com permanente referência a elementos materiais que possibilitam a construção de réplicas pelo leitor.

As narrativas de Júlio Verne são alicerçadas em preceitos científicos, tanto em descrições de ordem qualitativa quanto na recorrente utilização das unidades de medidas Físicas. No seguinte trecho, que consiste na descrição de uma embarcação destinada a combater o suposto monstro, podemos notar tais características narrativas:

[...] A escolha da fragata fora feliz, ela estava perfeitamente equipada para a aventura. Além de se tratar de barco veloz, fora provida de superaquecedores que tornavam possível elevar a sete atmosferas a tensão do vapor. Sob tal pressão, o Abraham Lincoln alcançava velocidade média de dezoito milhas e três décimos por hora, certamente considerável, contudo insuficiente para a luta contra o gigantesco cetáceo (VERNE, 1972, p. 25, grifo nosso).

O conceito de pressão ${ }^{2}$ no âmbito da termodinâmica - por Verne definido como tensão do vapor - ganha "vida", pois é o que impulsionará a embarcação

\footnotetext{
${ }^{2}$ Pressão ou tensão mecânica (p) é a força realizada sobre unidade de área (perpendicular à área). O termo atmosfera (atm) refere-se a uma unidade de pressão. Essa unidade é reconhecida, mas não faz parte do Sistema Internacional de Unidades. No SI a unidade de pressão é o Pascal (Pa) (HALLIDAY et al., 2002).
} 
para o combate. A potência dos superaquecedores da fragata é o que imprimirá a velocidade média de dezoito milhas e três décimos por hora.

[...] A máquina, o lastro, os diversos acessórios e instalações, as divisões estanques e as armações interiores têm o peso de novecentos e sessenta e uma toneladas e seiscentos e vinte quilos que adicionadas a trezentas e noventa e quatro toneladas e novecentos e sessenta quilos somam o total necessário de mil, trezentas e seis toneladas e quatrocentos e oitenta quilos. Compreendeu?

- Compreendi.

- Portanto - continuou o capitão Nemo -, quando o submarino Náutilus flutua nestas condições, apenas a sua décima parte emerge. Ora, se eu dispuser de reservatórios, cuja capacidade seja igual a este décimo, isto é, que possam conter cento e cinqüenta toneladas e setecentos e vinte quilos e, se eu os encher de água, o barco, passando a deslocar mil, quinhentas e sete toneladas, fica completamente submerso (VERNE, 1972, p. 92).

Nesse excerto, podemos notar a inserção de conceitos físicos em situações altamente contextualizadas, que permite ao leitor uma construção de sentidos, indispensável para um entendimento efetivo do objeto de estudo. Em um esquema simplificado (Fig. 2) ${ }^{4}$, teríamos:

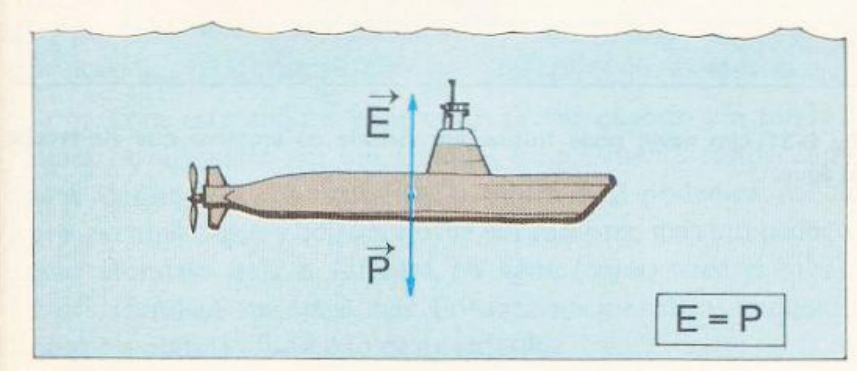

Fig. 8-28: Se um corpo está flutuando totalmente mergulhado em um liquido, seu peso é igual ao empuxo que ele está recebendo.

Fig. 2 - Submarino submerso.

\footnotetext{
${ }^{3}$ Velocidade (v) é a medida da rapidez com a qual um corpo altera sua posição. A velocidade média, que é uma medida da velocidade, é a razão entre um deslocamento e o intervalo de tempo levado para efetuar esse deslocamento (HALLIDAY et al., 2002).

${ }^{4}$ Máximo e Alvarenga (1997, p. 359) apresentam várias situações onde: E > P; E < P e $\mathrm{E}=\mathrm{P}$.
} 
O discurso científico surge como um elemento reforçador do discurso da ficção, das situações enunciadas na aventura e vice-versa. Júlio Verne, no tocante à estética de seu discurso, preza por valores numéricos, signos matemáticos e físicos, fazendo com que o caráter fantasioso da sua narrativa ganhe vida, aproximando-o da realidade científica, muitas vezes colocando em cheque os limites que separam a ciência e a ficção científica.

Alguns fragmentos de "Vinte Mil Léguas Submarinas" apresentam também conceitos de outras áreas do conhecimento científico, como a geografia, a geologia e a biologia marinha, podendo-se dizer, enfim, que Júlio Verne abrange, em sua narrativa, muitas perspectivas e manifestações científicas.

Um trecho ilustra bem essa abrangência:

[...] Enquanto eu observava, assim, aquele ser fenomenal, esguicharam de seus respiradouros dois jatos de água, que se elevaram a uma altura de quarenta metros, revelando-me sua maneira de respirar. Desse jato concluí, de maneira definitiva, que o animal pertencia ao ramo dos vertebrados, classe dos mamíferos, subclasse dos monodelfos, grupo dos pisciformes, ordem dos cetáceos... A ordem dos cetáceos compreende três familias: as baleias, os cachalotes e os delfins, estando os narvais compreendidos nesta última. Cada uma dessas famílias divide-se em vários gêneros, cada gênero em espécies, cada espécie em variedades (VERNE, 1972, p. 43).

Muitas outras passagens do livro elucidam aspectos teóricos de diversas áreas da ciência, entretanto, não sendo esse o foco do trabalho, trataremos, mais especificamente, dos conceitos/assuntos da Física.

Em concordância com Bakhtin (1997), o sentido estabelecido em um discurso, ou seja, a significação que um texto pode ter para o leitor, é um parâmetro tão indispensável quanto o espaço e o tempo no qual um evento possa ocorrer. Um discurso, para ser levado ao leitor, com uma fundamentação estética e linguística, precisa estar apoiado nos três parâmetros - espaço, tempo e sentido. A narrativa de Júlio Verne possibilita ao leitor o uso de sua imaginação para que possa construir um sentido sobre o que lê, entretanto, sem perder o embasamento científico envolvido.

Na citação a seguir, o autor dá uma aula de Física por meio de um diálogo que se assemelha ao de um professor com seu aluno, metodologia que, no século 
XVII, Galileu já utilizava, ao simular diálogos entre personagens defendendo posicionamentos científicos ${ }^{5}$.

[...] Assim, pois, a dez metros abaixo da superficie do mar sofrer-se-á pressão de dezessete mil, quinhentos e sessenta e oito quilogramas. A mil metros, cem vezes essa pressão, ou seja, dezessete milhões, quinhentos e sessenta e o oito mil quilogramas. [...] o corpo seria esmagado, como se o colocassem entre pratos de prensa hidráulica! (VERNE, 1972, p. 31)

No diálogo em que os personagens Ned Land e o professor Aronnax lançam uma situação hipotética, fica evidente como os conceitos apresentados podem ganhar um sentido mais amplo, considerando que o leitor pode colocar-se no lugar de um mergulhador, por exemplo, em grandes (e exageradas) profundidades, testando imaginariamente os princípios da hidrostática ${ }^{6}$.

O princípio de Stevin, que consiste em explicar a variação da pressão hidrostática devida unicamente a diferentes profundidades no mesmo líquido, foi levado a uma situação-limite na narrativa de Verne. Um mergulhador, tendo cada parte do seu corpo sujeita a uma alta pressão, independente dos valores numéricos, pode ser um exemplo esclarecedor, possibilitando ao leitor que "se transporte" para tal situação, levado pela sua imaginação, dando sentido aos conceitos estudados. Não é necessário mergulhar a centenas de metros de profundidade no oceano para experimentar a sensação, pelo menos na imaginação, do que são, de fato, a pressão hidrostática e suas consequências. A diferença de pressão exercida pelo ar e pela água também é tratada de maneira singular, possibilitando que, a partir do diálogo, assuntos interdisciplinares relacionados a mergulho (embolia traumática, rompimento de tímpano, hiperventilação, náuseas etc.), sejam abordados com leitura de pretexto, prática que Júlio Verne fomenta enormemente em toda a sua obra.

Por se tratar de uma obra de ficção científica verniana, em certos momentos é difícil separar a ficção do real, o que não nos preocupa, pois é exatamente nesse ponto que uma atividade pedagógica se torna mais abrangente, tendo em

\footnotetext{
5 Em 1632, Galileu publicou Diálogo sobre os dois principais sistemas do mundo, onde apresentava um debate entre três personagens: Salviati (defensor do heliocentrismo), Simplício (defensor do geocentrismo e um pouco ingênuo) e Sagredo (neutro, mas que termina por concordar com Salviati) (MASON, 1962, p. 116-126).

${ }^{6}$ Também chamada estática dos fluidos ou fluidostática - hidrostática se refere à água, que foi o primeiro fluido a ser estudado. Assim, por razões históricas, mantém-se o nome - é a parte da Física que estuda as forças exercidas por e sobre fluidos em repouso (HALLIDAY et al., 2002).
} 
vista que os conceitos de real e irreal, importantes no desenvolvimento cognitivo do indivíduo, são trazidos à tona. Como aponta Zanetic (2006), os livros didáticos também estão repletos de obstáculos epistemológicos como esse, cabendo-nos problematizá-los com os alunos, potencializando, assim, uma rica experiência pedagógica.

Cumpre enfatizar que em "Vinte Mil Léguas Submarinas", são diversas as menções que Júlio Verne faz a conceitos de Física, algumas vezes até poéticas:

[...] Os maquinistas puseram em movimento a roda motriz. O vapor silvou, precipitando-se nos cilindros, e os longos êmbolos horizontais gemeram comprimidos, impulsionando as bielas. As pás das hélices bateram a água com rapidez crescente e a Abraham Lincoln largou majestosamente, em meio a uma centena de barcas e lanchas repletas de espectadores, que the formaram cortejo (VERNE, 1972, p. 26).

Esse trecho se refere a uma máquina térmica, ilustrando o ciclo de Carnot ${ }^{7}$, porém, com palavras pouco convencionais, se tomarmos como referência os livros didáticos de Física para o Ensino Médio. As Fig. 3 e 4 (BONJORNO et al., 2001, p. 264-265) são exemplos de simplificações/abstrações frequentes nos livros didáticos:

\section{Basicamente, as máquinas térmicas funcionam seguindo um mesmo esquema.}

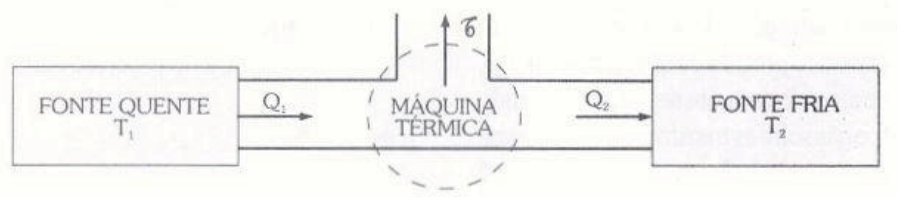

Fig. 3 -Diagrama para o funcionamento de uma máquina térmica

Podemos fazer uma analogia entre a descrição verniana e a encontrada nos livros didáticos, a dos gráficos, das isotermas do ciclo da máquina térmica de Carnot (Fig. 4). Embora a situação Física seja a mesma, Verne dá à narrativa um acabamento artístico. Bakhtin (1997, p. 203) afirma que

\footnotetext{
${ }^{7}$ Ciclo executado pela máquina de Carnot, idealizada pelo engenheiro francês Nicolas Léonard Sadi Carnot, que tem funcionamento apenas teórico. O rendimento da Máquina de Carnot é o máximo que uma máquina térmica trabalhando entre dadas temperaturas da fonte quente e da fonte fria pode ter (nunca chegando a 100\%) (HALLIDAY et al., 2002).
} 
a obra de arte é um acontecimento artístico vivo, significante, no acontecimento único da existência, e não uma coisa, um objeto de cognição puramente teórico, carente de um caráter de acontecimento significante e de um peso de valores.

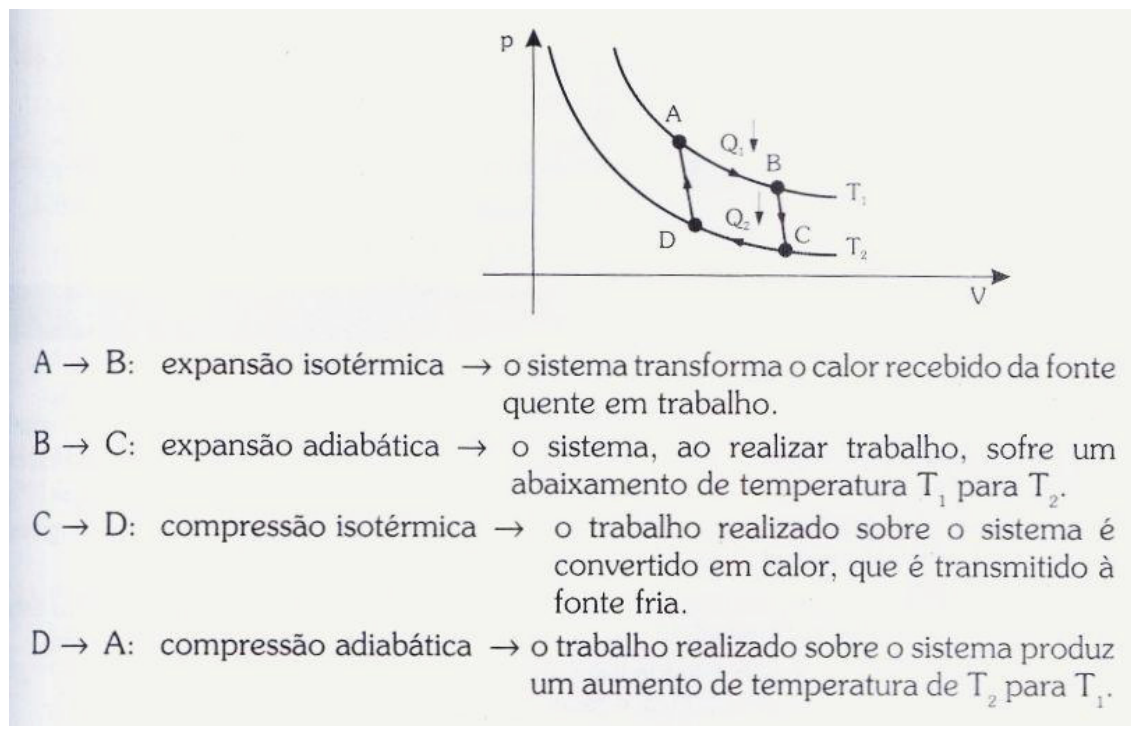

Fig. 4 - Ciclo de Carnot.

O estilo pelo qual Júlio Verne conduz suas narrativas faz com que o seu gênero discursivo se desloque constantemente entre o literário e o científico. $\mathrm{O}$ leitor atento aos conceitos científicos e a suas influências na vida cotidiana enxerga, na literatura de Verne, uma riqueza de possíveis leituras do mundo. Consonantes com Almeida (2004), vemos na literatura também possíveis leituras escolares do discurso científico. Um bom exemplo é a seguinte passagem:

[...]Há um agente poderoso, obediente, veloz, de fácil manejo, que se amolda a todos os usos e que reina como senhor absoluto a bordo do Náutilo. Ele, aqui, tudo faz. Ilumina, aquece, é vida e alma de meus aparelhos mecânicos. Este agente onímodo é a eletricidade (VERNE, 1972, p. 86). 
A descrição ímpar que faz da eletricidade ${ }^{8}$ traz em si o devaneio característico do romance, da poesia, quase sempre tão distante das obras da ciência. Ainda que, do ponto de vista científico, tal descrição não seja ratificada, ela é importante na medida em que estabelece valores e, em sintonia com Bakhtin (1997), dá sentido e abrilhanta, além de "dar vida" ao conceito.

Imerso em um universo científico, Júlio Verne compôs suas histórias atento à ampla produção da área no século XIX, enxergando implicações futuras desse conhecimento e as apresentando ao seu leitor. Uma dessas antecipações do escritor em relação ao que era conhecido em sua época foi o submarino Náutilus, que além de inspirar cientistas e engenheiros na construção dos submarinos no futuro, alimentou a imaginação do grande romancista Raul Pompéia. Olavo Bilac, Graça Aranha, Graciliano Ramos e Brito Broca também apreciaram os livros de Verne (PINTO NETO, 2004, p. 13-14).

Outro exemplo de tratamento literário a um assunto científico é o que segue:

[...] Todos conhecem a diafaneidade do mar. Todos sabem que sua transparência ultrapassa a da água doce. As próprias substâncias minerais e orgânicas que ela tem em suspensão aumentam-lhe a transparência. [...] Já não era água luminosa, era luz líquida (VERNE, 1972, p. 103).

Nesse trecho, Verne se refere à luz como se fosse de natureza material, líquida, ideia aparentemente absurda, se considerada do ponto de vista da Física clássica. Entretanto, a descrição não choca, levando-se em consideração a dualidade onda/partícula ${ }^{9}$ da luz oriunda da Física quântica. É claro que a situação narrada por Verne é desprovida de qualquer rigor científico, pois a dualidade da luz elucida casos específicos, onde ocorra sua interação com a matéria, mas acaba divulgando, independentemente da intenção do autor e da validade científica, teorias modernas, ausentes nas aulas de Física do Ensino Médio.

\footnotetext{
${ }^{8}$ Eletricidade (do grego elektron, que significa âmbar,) é um fenômeno físico originado por cargas elétricas estáticas, ou em movimento, e por sua interação. Quando uma carga se encontra em repouso, produz forças sobre outras situadas à sua volta (HALLIDAY et al., 2002).

9 A dualidade onda-partícula, também denominada dualidade onda-corpúsculo ou dualidade matéria-energia, constitui uma propriedade básica da mecânica quântica e consiste na capacidade das partículas subatômicas de se comportarem ou terem propriedades tanto de partículas como de ondas. (HALLIDAY et al., 2002)
} 
Ainda nesse trecho, vale salientar a maestria de Verne na intenção de descrever o grau de transparência da água do mar perpassada pela luz, estimulando vertiginosamente a imaginação do leitor. A título de ilustração da teoria bakhtiniana, à palavra "luz" são conferidas diferentes concepções, inclusive a religiosa que, através do discurso teológico, reitera o caráter polissêmico das palavras diante de enunciações e contextos diversos (BAKHTIN, 2009).

A preocupação com o conceito científico presente é sempre importante, pois, na ficção, os limites entre o real e o fantasioso são amiúde separados por uma linha tênue; porém, a problematização de um conteúdo, de uma situação como a descrita, é sempre melhor do que a ausência dela. Um professor bem preparado, com os conteúdos previamente adquiridos, pode perfeitamente trazer para a sala de aula questões sobre Física a partir da narrativa ficcional.

Outra característica interessante de "Vinte Mil Léguas Submarinas" é a menção que Verne faz às conquistas científicas e aos grandes cientistas:

[...] Seria Nemo algum sábio desconhecido, moderno Galileu, ou seria algum cientista, cuja carreira a política cortara? (VERNE, 1972, p. 100)

[...] Todos estes objetos, mergulhados na água, perdiam parte do peso igual à do líquido que deslocavam e esta lei, descoberta por Arquimedes, causava-me grande satisfação (VERNE, 1972, p. 117).

Esse último trecho é muito semelhante às definições dos livros didáticos, como ilustra a Fig. 5 (MÁXIMO; ALVARENGA, 1997, p. 358):

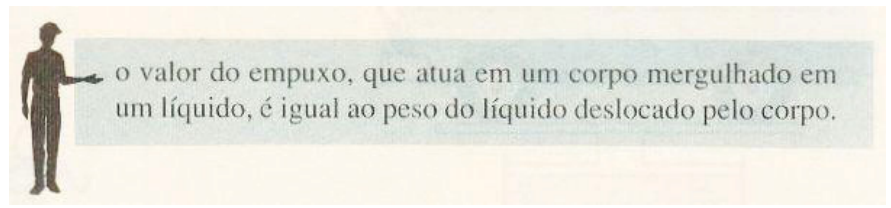

Fig. 5 - Definição de Empuxo.

Confirmando a proximidade de Verne com a ciência e a influência que dela recebia, alguns cientistas são citados nas falas dos seus personagens, como na passagem em que compara o personagem Capitão Nemo com Galileu. Nas palavras de Bakhtin, menções como essa podem ter a seguinte procedência:

O autor não encontra uma visão do herói que se assinale de imediato por um princípio criador e escape ao aleatório, uma reação que se assinale de imediato por um princípio produtivo; e não é a partir de uma relação de va- 
lores, de imediato unificada, que o herói se organizará em um todo: o herói revelará muitos disfarces, máscaras aleatórias, gestos falsos, atos inesperados que dependem das reações emotivo-volitivas do autor; este terá de abrir um caminho através do caos dessas reações para desembocar em sua autêntica postura de valores e para que o rosto da personagem se estabilize, por fim, em um todo necessário (BAKHTIN, 1997, p. 26).

Entendemos que o herói seria o capitão Nemo, e em sua constituição, Júlio Verne lança mão de uma autêntica referência de valores, de autoridade e muita representatividade nas ciências: Galileu Galilei. O personagem surge de uma relação importante que o autor tem com as ciências e, devido a uma comparação como a feita, não nos resta dúvida de que é o herói, assim como Bakhtin denomina.

É evidente que as citações de Verne não surgiram ao acaso. As influências sofridas pelo autor estão estampadas constantemente em seu texto, assim como em toda sua obra, apoiada na autoridade, testada e comprovada pela história da ciência, de nomes como Galileu e Arquimedes, entre outros. Entretanto, o seu princípio criador e as suas relações emotivo-volitivas despertam curiosidade, fascinam, e é nesse ponto que a análise de Bakhtin se faz importante: tanto as influências de Verne quanto o perfil de leitor esperado pelo autor definem o gênero discursivo pelo qual conduz suas histórias.

\section{Considerações finais}

É possível verificar, na obra de Júlio Verne, algumas características favoráveis à divulgação das ciências, à apresentação de conceitos e à contextualização de temas presentes nos livros didáticos. Nota-se, também, com o crivo da teoria de Bakhtin, recorrentes apropriações de gêneros nas narrativas vernianas. Todas essas particularidades, a nosso ver, podem propiciar ao aluno o desenvolvimento da capacidade de interpretar com mais propriedade assuntos científicos e igualmente os não científicos, em uma ampla diversidade de contextos, tornando-o, acima de tudo, um leitor do mundo que o rodeia.

Assim, a obra de Júlio Verne possui grande potencial como fonte de contextualização do conhecimento científico, em situações similares às apresentadas nos exercícios escolares, enriquecidas, porém, pela aventura, pelo enredo, pela descrição detalhada dos seus vários elementos composicionais.

Notamos, assim, em Júlio Verne, uma didática das ciências, caracterizada pela intencionalidade do autor em ensinar conceitos científicos às pessoas do seu tempo e, simultaneamente, tornando-se um divulgador da ciência. Em vários tre- 
chos dos livros, notam-se diálogos entre professor e aprendiz, no sentido lato dos termos, e devido à forma minuciosamente elaborada pela qual o autor conduz tais ocasiões, fica claro o caráter pedagógico que o texto acaba assumindo. A leitura dos livros de Júlio Verne pode representar o primeiro contato do leitor com determinadas ideias ou termos científicos, se levarmos em consideração a ampla faixa etária dos leitores ou, em outros casos, novas formas de contextualização de conceitos já aprendidos. Mediada pelo professor em aulas de Física, essa leitura pode enriquecer tanto a compreensão dos conceitos científicos quanto os sentidos construídos sobre outros gêneros.

Remetendo-nos às categorias de leitura de Geraldi, a nosso ver, o legado literário de Júlio Verne é muito abrangente. Além da leitura de fruição, - característica intrínseca às obras de ficção científica de grandes autores como Júlio Verne, Herbert George Wells, Arthur Clarke, entre outros - oferece condições de realização do estudo do texto e no texto. Ainda que o trabalho com livros de ficção, como os do autor estudado, não substitua o ensino de Física e de ciências para a apreensão de conceitos, expressões matemáticas, esquemas e gráficos, entre outros, tendo em vista que não é esse o objetivo do gênero, sua leitura, no entanto, pode complementar esse estudo, oferecendo aos alunos outras perspectivas para os conhecimentos, entre elas a de suas aplicações na vida real e a de seu caráter histórico.

$\mathrm{Na}$ teoria de Bakhtin, a riqueza na composição do tema emana da diversidade dos elementos verbais e não verbais que o constituem. A literatura e a ciência podem reciprocamente compartilhar inúmeros pontos de apoio e também de conflito. $\mathrm{O}$ conflito conceitual gerado na aproximação entre o discurso da literatura e o discurso científico não é preocupante no contexto do ensino e da aprendizagem, comparado às possibilidades de construções mais amplas de sentidos que a leitura de textos de ficção científica pode suscitar, não somente no âmbito escolar.

No que diz respeito à leitura de fruição do texto postulada por Geraldi (2006, p. 92), pode-se afirmar que, em relação à obra de Verne, ela ocorre de forma despretensiosa, fortuita e sem aprofundamentos contextuais, mas pode também ser mais profunda, estabelecendo múltiplas relações com outras esferas, tanto da literatura quanto das ciências, assim como da cultura geral. Com efeito, estabelecemos múltiplas e profundas relações com outras esferas sociais e culturais quando concebemos a literatura e a ciência como parcelas da cultura humana.

Retomamos, aqui, as críticas de Robilotta e Babichak (1997) à maneira simplificada como a Física é tratada nas salas de aula - como se um conceito encontrasse definição em si próprio e não estabelecesse qualquer relação com os demais - e que, inevitavelmente, inviabiliza a compreensão dos fenômenos estudados. Conduzido dessa forma, o ensino da disciplina acarreta aos alunos uma imen- 
sa dificuldade de construção de sentidos e de compreensão, bem como a de perceber a aplicabilidade do conhecimento físico.

Em sintonia com a proposta de João Zanetic, acreditamos que a literatura de Júlio Verne e a Física interagem recebendo reciprocamente pontos de apoio. A aproximação entre a literatura de ficção científica e o ensino da disciplina no âmbito escolar, quando realizada por um mediador atento à diversidade de contextos que emanam dessa relação, pode, sem dúvida, potencializar o ensino da Física concebida como cultura (FERREIRA, 2011).

Finalmente, conceber a Física como cultura, buscando o diálogo entre diferentes esferas discursivas, é, como este trabalho procurou mostrar, um caminho promissor, tanto no ensino e na aprendizagem de conceitos científicos, como no contexto das infindáveis possibilidades que a literatura proporciona a todas as pessoas que se permitem nela adentrar.

\section{Referências}

ALMEIDA, M. J. P. M. de. Discursos da Ciência e da Escola: Ideologia e Leituras Possíveis. Campinas: Mercado de Letras, 2004.

BAKHTIN, M. M. Estética da Criação Verbal. Tradução: Maria Ermantina G. Pereira. 2. ed. São Paulo: Martins Fontes, 1997.

Marxismo e Filosofia da Linguagem. Tradução: Michel Lahud e Yara Frateschi Vieira. 13. ed. São Paulo: Hucitec, 2009.

BONJORNO, R. A. et al. Física Completa. 2. ed. São Paulo: FTD, 2001. v. único.

FERREIRA, J. C. D. Aproximações entre a obra de Júlio Verne e o ensino de física. 2011. Dissertação (Mestrado) - Faculdade de Ciências e Tecnologia, UNESP, Presidente Prudente.

GERALDI, J. W. Prática de Leitura na Escola. In: GERALDI, J. W. (Org.). O texto na sala de aula. Campinas, SP: Ática, 2006. p. 88-103.

HALLIDAY, D.; RESNICK, R.; WALKER, J. Fundamentos de Física. 6. ed. Rio de Janeiro: Livros Técnicos e Científicos, 2002. 4 vol.

INEP (Instituto Nacional de Estudos e Pesquisas Educacionais Anísio Teixeira). PISA 2009: Relatório Nacional. Disponível em: 
$<$ http://portal.inep.gov.br/internacional-novo-pisa-resultados $>$. Acesso em: 25 fev. 2013.

MASON, S. F. História da Ciência: as principais correntes do pensamento científico. Rio de janeiro: Globo, 1962.

MÁXIMO, A.; AlVArEngA, B. Curso de Física. 4. ed. São Paulo: Scipione, 1997. 3 vol.

MEGID NETO, J.; FRACALANZA, H. O livro didático de ciências: problemas e soluções. Ciência \& Educação, v. 9, n. 2, 2003, p. 147-157.

PINTO NETO, P. da C. Júlio Verne: o propagandista das ciências. Ciência \& Ensino, n. 12, dez. 2004.

RAMALHO JÚNIOR, F.; FERRARO, N. G.; SOARES, P. A. de T. Os fundamentos da física. 5. ed. São Paulo: Moderna, 1988. 3 vol.

ROBILOTTA, M. R.; BABICHAK, C. C. Definições e conceitos em Física. Cadernos Cedes, Ano XVIII, n. 41, p. 35-45, jul. 1997.

VERNE, J. Vinte Mil Léguas Submarinas. Tradução: José Gonçalves Vilanova. São Paulo: Hemus, 1972.

ZANETIC, J. Física também é cultura. 1989. Tese (Doutorado) - Faculdade de Educação, USP, São Paulo.

Física é cultura. Ciência e Cultura, v. 57, n. 3, p. 21-24, july/sept, 2005.

Física e Arte: uma ponte entre duas culturas. Pro-Posições, v. 17, n. 1 (49), Campinas, 2006. 